\title{
Peran Petugas Kolektor Desa Dalam Meningkatkan Kepatuhan Wajib Pajak Dalam Membayar Pajak Bumi Dan Bangunan (Pbb-P2) Di Kabupaten Subang
} (Studi Kasus Pada Kecamatan Subang, Kecamatan Jalancagak dan Kecamatan Serangpanjang)

\author{
${ }^{1}$ Iman Roheman, ${ }^{2}$ Dian Anita \\ ${ }^{12}$ Sekolah Tinggi Ilmu Ekonomi STEMBI, Bandung, Indonesia
}

\begin{tabular}{l}
\hline Article Info \\
\hline Article history: \\
Received 10 Januari 2022 \\
Publish 11 Januari 2022
\end{tabular}

Keywords:

Taxpayer Compliance,

$P B B-P 2$,

Role.

\begin{abstract}
This research is motivated by the level of taxpayer compliance in paying Land and Building Tax, the lack of coordination between village collector officers and the Regional Revenue Agency, and the low performance in collecting Land and Building Taxes. The method in this study uses qualitative research. Primary data sources are 10 people. Data collection techniques in this study using interviews, observation and documentation. The data analysis technique uses data reduction, data presentation and drawing conclusions or verification. Test the validity of the data in this study using prolonged observation of increased persistence and triangulation. The results obtained in this study, the role of village collector officers in improving taxpayer compliance in paying PBB taxes in Subang District, Jalancagak District and Subang District has been implemented but not maximized. Not maximized based on the obstacles that occur, both internal and external obstacles. Internal obstacles include the lack of awareness of taxpayers in paying land and building taxes, lack of understanding of land and building taxes, lack of understanding of the main duties and functions of village collector officers and the economic condition of taxpayers. Meanwhile, external constraints include, where the tax subject is not known to the officer, the contents of the data are not in accordance with the tax object owned, multiple tax returns (SPPT) and regional expansion. The strategic efforts carried out are by providing counseling or socialization, increasing the level of land and building tax services and providing sanctions so that the achievement of the target of land and building tax revenue can be achieved.
\end{abstract}

Info Artikel

Article history:

Diterima 10 Januari 2022

Terbit 11 Januari 2022

\begin{abstract}
Penelitian ini dilatarbelakangi oleh tingkat kepatuhan wajib pajak dalam membayar Pajak Bumi dan Bangunan, kurangnya koordinasi antara petugas kolektor desa dengan Badan pendapatan daerah, dan rendahnya kinerja dalam memungut Pajak Bumi dan Bangunan. Metode dalam penelitian ini menggunakan penelitian kualitatif. Sumber data primer adalah 10 orang. Teknik pengumpulan data dalam penelitian ini menggunakan wawancara, observasi dan dokumentasi. Teknik analisis data menggunakan reduksi data, penyajian data dan penarikan kesimpulan atau verifikasi. Uji validitas data dalam penelitian ini menggunakan observasi berkepanjangan peningkatan ketekunan dan triangulasi. Hasil yang diperoleh dalam penelitian ini, peran petugas kolektor desa dalam meningkatkan kepatuhan wajib pajak dalam membayar pajak PBB di Kecamatan Subang, Kecamatan Jalancagak dan Kabupaten Subang sudah dilaksanakan namun belum maksimal. Belum maksimal berdasarkan hambatan yang terjadi, baik hambatan internal maupun eksternal. Hambatan internal antara lain kurangnya kesadaran wajib pajak dalam membayar pajak bumi dan bangunan, kurangnya pemahaman tentang pajak bumi dan bangunan, kurangnya pemahaman tentang tugas pokok dan fungsi petugas kolektor desa dan kondisi ekonomi wajib pajak. Sedangkan kendala eksternal meliputi, keberadaan subjek pajak tidak diketahui petugas, isi data tidak sesuai dengan objek pajak yang dimiliki, Surat Pemberitahuan Berganda (SPPT) dan pemekaran daerah. Upaya strategis yang dilakukan adalah dengan memberikan penyuluhan atau sosialisasi, meningkatkan tingkat pelayanan pajak bumi dan bangunan serta memberikan sanksi agar pencapaian target penerimaan pajak bumi dan bangunan dapat tercapai.
\end{abstract}


This is an open access article under the Lisensi Creative Commons AtribusiBerbagiSerupa 4.0 Internasional

\section{Corresponding Author:}

Imam Roheman,

Sekolah Tinggi Ilmu Ekonomi STEMBI

Email: Imanr6061@gmail.com

\section{PENDAhuluan}

Sumber utama pendapatan negara adalah pajak, yang akan digunakan untuk mendanai kegiatan pemerintah. Dengan tujuan untuk mensejahterakan masyarakat.. Dengan demikian, tanpa pajak, kemajuan negara akan sulit dilaksanakan. Selain itu, pajak digunakan untuk memberikan rasa amanuntuk masyarakat.dan guna menunjang jalannya roda pemerintahan dan pembiayaan pembangunan suatu negara.

Diindonesia, pajak dibagi menjadi dua diantaranya pajak provinsi dan pajak daerah. Pajak provinsi merupakan pajak yang dipungut oleh pemerintah pusat yang dikelola oleh Direktorat Jendral Pajak dibawah Departemen Keuangan. Sedangkan Pajak daerah merupakan pajak yang pungutannya dilakukan oleh pemerintah daerah, baik tingkat provinsi maupun tingkat kabupaten/kota. (Sumarsan, 2017).

Pajak yang dipungut oleh pemerintah daerah salah satunya yaitu Pajak Bumi dan Bangunan (PBB). Pajak Bumi dan Bangunan (PBB) adalah pajak yang kewajibannya dibebankan kepada wajib pajak orang pribadi atau badan atas bumi dan atau bangunan yang dimiliki atau digunakan. (Josep,2018:36)

Diindonesia yang menjadi kendala dalam pengumpulan pajak yaitu kepatuhan wajib pajak. Kepatuhan untuk menjadi wajib pajak yang patuh perlu pembinaan melalui pendekatan kalbu wajib pajak sehingga roda pemerintahan akan berjalan lancar dan terciptanya cita - cita masyarakat dalam bernegara. Dan setiap wajib pajak harus sadar akan kewajibannya yaitu membayar pajak khususnya pajak PBB untuk melancarkan kegiatan pemerintahan. (Tuti 2018).

Permasalahan wajib pajak ketidakpatuhan dalam membayar pajak bumi dan bangunan terjadi pada kabupaten subang. Dimana target yang ditetapkan yaitu $100 \%$ tetapi kabupaten subang hanya mencapai $62,69 \%$. Dalam skala kecil terdapat beberapa kecamatan yang sulit untuk mencapai target yang ditentukkan yaitu kecamatan subang, kecamatan jalancagak dan kecamatan serangpanjang. Dapat dilihat dalam tabel dibawah ini :

Tabel 1. Realisasi PBB-P2 per Kecamatan Tahun 2020

\begin{tabular}{|r|l|c|c|c|c|c|c|}
\hline \multirow{2}{*}{ No } & \multirow{2}{*}{ Uraian } & \multicolumn{2}{|c|}{ Pokok } & \multicolumn{2}{c|}{ Realisasi } & \multicolumn{2}{c|}{ Pencapaian } \\
\cline { 3 - 8 } & & WP & \multicolumn{1}{c|}{ Rp } & WP & Rp & WP & $\%$ \\
\hline 1 & Subang & 55.347 & 4.047 .924 .990 & 29.601 & 2.052 .265 .975 & 29.601 & $50,70 \%$ \\
\hline 2 & Jalancagak & 30.577 & 1.127 .024 .082 & 16.978 & 655.383 .308 & 16.978 & $58,15 \%$ \\
\hline 3 & Serangpanjang & 23.862 & 732.041 .852 & 22.578 & 688.712 .763 & 22.578 & $94,08 \%$ \\
\hline
\end{tabular}

Sumber : Bapenda, 2021

Adapun Berdasarkan hasil wawancara dan observasi peneliti dilapangan dan data yang didapat dikecamatan Subang, Kecamatan Jalancagak Dan Kecamatan Serangpanjang tedapat permasalahanpermasalahan yang dihadapi petugas kolektor desa, diantaranya :

1. Rendahnya kepatuhan wajib pajak dalam membayar pajak Bumi dan Bangunan

2. Kurangnya kordinasi antara petugas kolektor desa dengan badan pendapatan daerah (BAPENDA). Hal ini karena setiap tahun sering terjadi double data atau disebut dengan double anclah. Hal ini 
dapat dilihat dari alasan petugas kolektor desa setiap tahun selalu ada data yang sama, baik nama, luas, tahun, dan NOP sehingga besaran target akan tidak tercapai.

3. Rendahnya kinerja petugas kolektor desa dalam melakukan penagihan pajak bumi dan bangunan (PBB-P2).

Dari pemaparan diatas, masih terdapat perbedaan dari penelitian terdahulu. Perbedaan hasil penelitian mungkin saja terjadi karena ada perbedaan - perbedaan yang dapat mempengaruhi tingkat kepatuhan wajib pajak dalam membayar Pajak Bumi dan Bangunan (PBB-P2). Dalam penelitian sebelumnya Tuti Wahyuni (2018) menggunakan variabel perangkat desa dalam meningkatkan kepatuhan wajib pajak dalam membayar Pajak Bumi dan Bangunan. Setelah melakukan pengamatan perangkat desa dijadikan sebagai motivator untuk meningkatkan semangat petugas kolektor desa dalam memungut Pajak PBB. Hal ini yang menjadi peneliti tertarik untuk meneliti kembali dengan menggunakan variabel yang lebih spesifik yaitu Petugas Kolektor Desa yang dalam meningkatkan kepatuhan wajib pajak untuk membayar Pajak Bumi dan Bangunan (PBB-P2).

\subsection{Rumusan Masalah}

2. Bagaimana peran petugas kolektor desa dalam meningkatkan kepatuhan wajib pajak dalam membayar pajak bumi dan bangunan?.

3. Apa saja hambatan - hambatan yang dihadapi petugas kolektor desa dalam meningkatkan kepatuhan wajib pajak dalam membayar pajak bumi dan bangunan?.

4. Bagaimana strategi yang dilakukan petugas kolektor dalam mencapai target yang ditetapkan?

\section{TINJAUAN PUSTAKA}

\subsection{Peran}

Peran merupakan kegiatan seseorang atau sekelompok orang dalam melaksanakan hak dan kewajibannya sesuai dengan kedudukan (status) yang akan menghasilkan suatu perubahan. Sehingga ia dapat menjalankan peranan seseorang atau sekelompok orang tersebut. (Soekanto dalam Agung, 2017)

\subsection{Petugas Kolektor Desa}

Petugas Kolektor desa merupakan pegawai desa yang diberikan tugas pokok dan fungsi khusus oleh kepala desa yaitu melakukan pendistribusian SPPT dan mengumpulkan penagihan pajak bumi dan bangunan yang ada didesa, untuk selanjutnya disetor ke kas negara melalui bank yang telah ditetapkan.

\subsection{Pajak}

Pajak adalah iuran dari rakyat sifatnya memaksa kepada kas negara yang terutang, berdasarkan undang - undang, dengan tidak mendapatkan jasa timbal balik dan akan digunakan untuk membiayai pegeluaran pemerintah. (Agus \& Estralita, 2018:6)

\subsection{Wajib Pajak}

Wajib pajak merupakan orang pribadi atau badan yang melakukan kewajibannya termasuk dengan pemungut atau pemotong pajak tertentu berdasarkan dengan peraturan perundang undangan perpajaakan yang ditentukkan. (Mardiasmo dalam Julia Filia, 2015;25)

\subsection{Kepatuhan Wajib Pajak}

Kepatuhan wajib pajak adalah wajib pajak yang melaksanakan kewajibannya dalam membayar pajak sesuai dengan ketentuan peraturan perpajakan yang berlaku . (Rahayu dalam Wahyuni 2010:138)

\subsection{Pajak Bumi dan Bangunan}

Pajak Bumi dan Bangunan adalah pajak yang sifatnya kebendaan yang tidak ditentukkan oleh subjek pajak dengan tidak menentukan besaran pajaknya. Tetapi ditentukkan dengan keadaan objek pajak yaitu bumi dan atau bangunan dengan berdasarkan official assesment system. (Soedarmayanti, 2013) 


\section{METODE PENELITIAN}

\subsection{Objek Penelitian dan Lokasi Penelitian}

Objek penelitian dalam penelitian ini, yaitu wajib pajak yang membayar PBB. Dengan lokasi penelitiannya di Kecamatan Subang, Kecamatan Jalancagak dan Kecamatan Serangpanjang di Kabupaten Subang.

\subsection{Paradigma Penelitian}

Paradigma yang digunakan dalam penelitian ini yaitu, paradigma Fenomenologis dimana peneliti menyebutkan suatu peristiwa dipandang secara tunggal dan menjadikan manusia sebagai alasan apa saja untuk bertindak. Baik disadari ataupun tidak disadari, dengan paradigma fenomologis akan menggali faktor yang terjadi dibalik fenomena sehingga proses penelitian yang dianggap penting.

\subsection{Metode Penelitian}

Dalam jenis penelitian ini menggunakan kualitatif dimana lebih berfokus pada proses petugas kolektor pajak desa dalam memungut Pajak Bumi dan Bangunan dari pada hasil akhir. Jadi dalam Penelitian kualitatif merupakan penelitian tentang riset peranan petugas kolektor pajak desa dalam memungut Pajak Bumi dan Bangunan yang bersifat deskriptif dan lebih menggunakan analisis. Penelitian kualitatif dapat diketahui cara pandang objek peneliti lebih mendalam tentang riset peranan petugas kolektor pajak desa dalam memungut Pajak Bumi dan Bangunan yang tidak diwakii dengan angka-angka statistik.

\subsection{Sampel Penelitian}

Kriteria yang telah ditetapkan, maka peneliti menetapkan sebanyak 10 dijadikan sebagai subjek penelitian. Maka dari itu atas yang telah dibuatkan rincian pengambilan sampel subjek pajak adalah sebagai berikut :

Tabel. 2. Teknik Pengambilan Sampel Subjek Penelitian

\begin{tabular}{|l|l|l|}
\hline \multicolumn{1}{|c|}{ No } & \multicolumn{1}{|c|}{ Status } & \multicolumn{1}{|c|}{ Jumlah } \\
\hline 1. & Petugas Kolektor Desa Kecamatan Subang & 1 orang \\
\hline 2. & Petugas Kolektor Desa Kecamatan Jalancagak & 1 orang \\
\hline 3. & Petugas Kolektor Desa Kecamatan Serangpanjang & 1 orang \\
\hline 4. & Wajib Pajak Dikecamatan Subang & 2 orang \\
\hline 5. & Wajib Pajak Dikecamatan Jalancagak & 2 orang \\
\hline 6. & Wajib Pajak Dikecamatan Serangpanjang & 2 orang \\
\hline 7. & Petugas Bapenda Kab. Subang & 1 orang \\
\hline Jumlah & $\mathbf{1 0}$ orang \\
\hline
\end{tabular}

$$
\text { Sumber : Data diolah oleh penulis }
$$

\subsection{Sumber Data}

Sumber Data yang digunakan dalam penelitian ini yaitu data primer. Data primer yaitu data yang didapatkan secara langsung dari narasumber yang tepat.

\subsection{Subjek Penelitian}

Subjek penelitian dalam penelitian ini yaitu Petugas Kolektor Desa dan Wajib Pajak serta Petugas Badan Pendapatan Daerah (BAPENDA) kab. Subang.

\subsection{Teknik Pengumpulan Data}

Teknik pengumpulan data dalam penelitian ini menggunakan Wawancara, Observasi dan Dokumentasi.

\subsection{Teknik Analisis Data}

Dalam penelitian ini, melakukan analisis data pada saat pengumpulan data berlangsung dengan cara Reduksi data, yaitu melakukan pengumpulan data melalui wawancara kepada narasumber. Setelah data terkumpul dari hasil wawancara kemudian melakukan Penyajian data yaitu menguraikan data dengan bersifat naratif. Kemudian tahap akhir menggunakan Verification 
yaitu melakukan penarik kesimpulan berdasarkan data yang ada dari hasil wawancara kepada narasumber.

\subsection{Pengujian Validitas Data}

Dalam penelitian ini menggunakan uji keabsahan data yang dipakai oleh peneliti yaitu Perpanjangan Pengamatan, Peningkatan Ketekunan Dan Trianggulasi.

\section{HASIL TEMUAN DAN PEMBAHASAN}

\subsection{Gambaran Umum}

Pengelolaan Pajak Bumi dan Bangunan (PBB-P2) dikabupaten subang dilaksanakan oleh beberapa bidang yang ada di Badan Pendapatan Daerah (BAPENDA) Kabupaten Subang. Dengan begitu, berdampak terhadap kurang maksimalnya pencapaian target realisasi penerimaan Pajak Bumi dan Bangunan (PBB-P2) dikabupaten Subang. Kewenangan masih dipegang oleh pemerintahan pusat melalui Ditjen Pajak Kemenkeu, tetapi dalam pendistribusian sampai ke wajib pajak, yaitu Pajak Bumi dan Bangunan (PBB-P2) diserahkan kepada pemerintah Desa. Pemerintah Desa menunjuk petugas Pajak Bumi dan Bangunan (PBB-P2) dalam memungut Pajak Bumi dan Bangunan (PBB-P2), tetapi petugas tersebut tidak memahami keuangan, serta pemerintah desa yaitu Kepala Desa bertanggung jawab atas pencapaian Realisasi Pajak PBB yang telah dibebankan, sekaligus melaksanakan sosialisasi, pembinaan, dan pengawasan pajak bumi dan bangunan dimasing - masing Desa atau/ Kelurahan. Tetapi, jika terjadi permasalahan mengenai Pajak Bumi dan Bangunan (PBB-P2), biasanya petugas kolektor desa langsung yang mengurus suatu permasalahan dan sekaligus menjadi ujung tombak dalam penerimaan Pajak Bumi dan Bangunan (PBB-P2) di Badan Pendapatan Daerah Kab. Subang. Selain itu petugas kolektor diberikan tugas khusus untuk melakukan menyampaikan SPPT dan mengumpulkan besaran Pajak Bumi dan Bangunan diwajib pajak yang nantinya akan disetor keKas Negara melalui Bank yang ditunjuk.

Pemerintahan Daerah, Badan Pendapatan Daerah menyadari, sangat berat menjadi petugas kolektor karena dengan tugas yang sangat berat. Oleh sebab itu, petugas Pajak Bumi dan Bangunan (PBB-P2) dalam menjalankan tugasnya diperkuat dengan Surat Keputusan (SK) Bupati yang berlaku selama satu tahun. Diharapkan dengan Surat keputusan (SK) tentang penunjukkan petugas Pajak Bumi dan Bangunan menjadi lebih sangat baik yang dilengkapi dengan tata cara pemungutan penerimaan Pajak Bumi dan Bangunan agar setiap menjalankan tugasnya bisa lebih jelas. Dengan tujuan, agar tidak terjadi suatu permasalahan yang terjadi seperti saling menyalahkan dalam memungut Pajak Bumi dan Bangunan.

Berdasarkan Peraturan Bupati Nomor KU.03..03.01/KEP-72-|Bapenda/2020 Tentang Penunjukkan Petugas Pajak Bumi dan Bangunan (PBB-P2) Sektor Perdesaan Dan Perkotaan Buku 1 dan 2 Se-Kabupaten Subang. Yang memiliki Tugas Pokok Dan Fungsi Petugas Pajak Bumi adalah sebagai berikut :

a. Menyampaikan SPPT - PBB Buku1 dan 2 kepada wajib Pajak

b. Mengembalikan Struk SPPT PBB sebagai Bukti telah diterima SPPT oleh wajib pajak.

c. Mensosialisasikan tempat pembayaran PBB kepada wajib pajak untuk membayar langsung keBank BJB, Kantor Pos, Alfamarret, Indomaret, Tokopedia, Bukalapak, Traveloka, Bumdes, dan tempat pembayaran lainnya yang sudah bekerja sama dengan Badan Pendapatan Daerah Kab. Subang.

d. Menghimpun permasalahan yang dihadapi dalam pelaksanaan pemungut Pajak Bumi dan Bangunan (PBB) untuk kemudian dilaporkan ke Bapenda Kab. Subang.

e. Bersama - sama dengan kepala desa/ kelurahan bertanggung jawab atas keberhasilan/pelunasan target PBB desa/kelurahan masing - masing. 


\subsection{Pembahasan}

Analisis Peran Petugas Kolektor dalam meningkatkan Kepatuhan Wajib Pajak dalam membayar Pajak Bumi dan Bangunan (PBB-P2). Pada kecamatan Jalancagak, kecamatan Subang dan Kecamatan Serangpanjang.

Tabel 3. Daftar Peneimaan PBB Pada Kecamatan Subang

\begin{tabular}{|r|c|c|c|c|c|c|c|}
\hline \multirow{2}{*}{ No } & \multirow{2}{*}{ Uraian } & \multicolumn{2}{|c|}{ Pokok } & \multicolumn{2}{c|}{ Realisasi } & \multicolumn{2}{c|}{ Pencapaian } \\
\cline { 3 - 8 } & & WP & Rp & WP & Rp & WP & $\%$ \\
\hline 1 & 2016 & 49.996 & 2.446 .081 .261 & 23.319 & 1.162 .772 .222 & 23.319 & $47,15 \%$ \\
\hline 2 & 2017 & 52.147 & 2.570 .055 .516 & 26.997 & 1.307 .572 .975 & 26.997 & $50,88 \%$ \\
\hline 3 & 2018 & 53.748 & 2.640 .117 .540 & 25.911 & 1.288 .933 .952 & 25.911 & $48,82 \%$ \\
\hline 4 & 2019 & 53.896 & 3.949 .338 .064 & 26.168 & 1.884 .051 .060 & 26.168 & $47,71 \%$ \\
\hline & 2020 & & & & & & \\
5 & & 55.347 & 4.047 .924 .990 & 29.601 & 2.052 .265 .975 & 29.601 & $50,70 \%$ \\
\hline
\end{tabular}

Sumber : Bapenda Kab. Subang, 2021

Tabel 4. Daftar Peneimaan PBB Pada Kecamatan Jalancagak

\begin{tabular}{|r|c|c|c|c|c|c|c|}
\hline \multirow{2}{*}{ No } & \multirow{2}{*}{ Uraian } & \multicolumn{2}{|c|}{ Pokok } & \multicolumn{2}{c|}{ Realisasi } & \multicolumn{2}{c|}{ Pencapaian } \\
\cline { 3 - 8 } & & WP & Rp & WP & Rp & WP & $\%$ \\
\hline 1 & 2016 & 28.783 & 616.885 .599 & 16.606 & 373.557 .706 & 16.606 & $60,56 \%$ \\
\hline 2 & 2017 & 29.070 & 630.867 .096 & 15.814 & 368.143 .721 & 15.814 & $58,36 \%$ \\
\hline 3 & 2018 & 29.345 & 641.500 .141 & 16.296 & 366.711 .951 & 16.296 & $57,16 \%$ \\
\hline 4 & 2019 & 29.731 & 1.080 .884 .310 & 16.900 & 631.104 .981 & 16.900 & $58,39 \%$ \\
\hline 5 & 2020 & 30.577 & 1.127 .024 .082 & 16.978 & 655.383 .308 & 16.978 & $58,15 \%$ \\
\hline
\end{tabular}

Sumber : Bapenda Kab. Subang, 2021

Tabel 5. Daftar Peneimaan PBB Pada Kecamatan Serangpanjang

\begin{tabular}{|r|c|c|c|c|c|c|c|}
\hline \multirow{2}{*}{ No } & \multirow{2}{*}{ Uraian } & \multicolumn{2}{|c|}{ Pokok } & \multicolumn{2}{c|}{ Realisasi } & \multicolumn{2}{c|}{ Pencapaian } \\
\cline { 3 - 8 } & & WP & Rp & WP & Rp & WP & $\%$ \\
\hline 1 & 2016 & 21.692 & 413.610 .423 & 16.379 & 299.526 .275 & 16.379 & $72,42 \%$ \\
\hline 2 & 2017 & 21.694 & 410.723 .273 & 15.317 & 279.930 .096 & 15.317 & $68,16 \%$ \\
\hline 3 & 2018 & 21.570 & 409.673 .158 & 14.799 & 275.516 .645 & 14.799 & $67,25 \%$ \\
\hline 4 & 2019 & 21.539 & 678.011 .664 & 15.482 & 471.468 .564 & 15.482 & $69,54 \%$ \\
\hline 5 & 2020 & 23.862 & 732.041 .852 & 22.576 & 688.712 .763 & 22.576 & $94,08 \%$ \\
\hline
\end{tabular}

Sumber : Bapenda Kab. Subang, 2021

Berdasarkan tabel diatas terlihat tidak mencapai target yang diinginkan. Hal ini dikarenakan kurang maksimalnya peran petugas kolektor dalam meningkatkan kepatuhan wajib pajak dalam membayar pajak PBB. Tidak mencapai target yang ditetapkan sering terjadi setiap tahun, permasalahan yang menyebabkan tidak tercapainya target. Dilihat berdasarkan dari segi kemampuan petugas kolektor desa dan kemauan wajib pajak dalam membayar pajak PBB.

1. Kemampuan Petugas Kolektor Desa

Pajak bumi dan bangunan perkotan dan perdesaan merupakan pajak yang memiliki pengaruh yang fotensial terhadap pendapatan asli daerah. Dan pajak bumi dan bangunan memiliki jumlah wajib pajak terbanyak. Untuk mencapai target yang ditetapkan perlu peran petugas kolektor desa yang gigih untuk meningkatkan kepatuhan wajib pajak agar target yang diinginkan dapat tercapai. Tetapi petugas kolektor desa pada kecamatan subang, kecamatan jalancagak dan kecamatan serangpanjang tidak maksimalnya peran petugas kolektor desa 
dalam meningkatkan kepatuhan wajib pajak dapat dilihat berdasarkan wawancara dibawah ini :

Menurut Bapak Alan Sunandar selaku petugas kolektor desa kecamatan Subang mengatakan :

"upaya dalam meningkatkan kepatuhan wajib pajak kami melakukan sosialisasi secara langsung kepada masyarakat. Sosialisasi yang saya lakukan melakukan pendekatan secara dekat kepada wajib pajak. Selain itu saya menggerakkan semua RT dan RW setempat untuk memberitahu, memungut Pajak PBB, guna kefektifan waktu dan RT dan RW setempatlah yang mengetahui secara pasti bagaimana keberadaan secara detail keberadaan wajib pajak dan biasanya RT dan RW melakukan penagihan yang bersifat terus - menerus kepada wajib pajak"

Selanjutnya Menurut Bapak Suara selaku Petugas Kolektor Desa Kecamatan Jalancagak mengatakan :

"upaya dalam meningkatkan kepatuhan wajib pajak, saya sering melakukan door the door ke rumah wajib pajak secara langsung untuk memberitahu besaran pajak yang harus dibayar. Sambil melakukan sosialisasi pentingnya membayar pajak saat memberi tahu besaran pajak tersebut. Sudah selelsai memberitahu saya menggerakkan RT setempat untuk menagih besaran pajak terutang, terkadang RT pun melakukan sosialisasi kepada wajib pajak dalam membayar Pajak Bumi dan Bangunan"

Selanjutnya menurut Bapak Atim Saputra selaku Petugas Kolektor Desa kecamatan Serangpanjang mengatakan :

"upaya dalam meningkatkan kepatuhan wajib pajak, saya melakukan sosialisasi kepada wajib pajak melalui acara rutinan yaitu pengajian ibu - ibu sambil membawa bukti pembayaran kepala desa yang telah bayar terlebih dahulu untuk memotivasi wajib pajak agar mendorong rasa keinginan wajib pajak dalam membayar Pajak bumi dan bangunan'

2. Kemauan wajib pajak

Menurut Bapak Ahmad selaku wajib pajak dikecamatan Subang mengatakan :

"petugas saat memberitahu besaran pajak PBB, petugas hanya memberitahu saja tanpa memberitahu apa itu pajak PBB, fungsinya buat apa, sehingga membuat saya tanda tanya."

Selanjutnya, menurut Bapak Rudi selaku wajib pajak dikecamatan subang mengatakan : "yang menjadi petugas pemungut pajak PBB ini petugas kolektor atau RT, ini yang membuat saya bingung dan mereka tidak melakukan sosialisasi mereka hanya memberitahu besaran pajak yang harus dibayarnya saja"

Selanjutnya, Menurut Bapak Encang selaku Wajib Pajak dikecamatan Jalancagak :

"petugas kolektor saat datang untuk menagih besaran pajak PBB saya langsung bayar karena dengan membayar pajak, pajak akan kembali kekita lagi"

Selanjutnya menurut Bapak Carman selaku wajib pajak di kecamatan Jalancagak mengatakan :

"petugas kolektor saat datang kerumah untuk menagih besaran pajaknya saja tanpa melakukan sosialisasi mengenai pajak bumi dan bangunan. Dan setelah bayar petugas langsung pulang kemudian memberikan SPPT."

Selanjutnya menurut $\mathrm{Bu}$ Nia selaku wajib pajak dikecamatan Serangpanjang, Mengatakan:

"saya tahu untuk membayar pajak bumi dan bangunan saya selalu bayar dibulan juli september. Diantara ketiga bulan tersebut karena sering ada penyuluhan mengenai pentingnya besaran pajak bumi dan bangunan melainkan petugas kolektor pun saat menagih sering melakukan sosialisasi penting Pajak PBB” 
Selanjutnya, menurut Bapak Oyo, selaku Wajib pajak dikecamatan Serangpanjang mengatakan:

"saya sering membayar pajak PBB karena menurut petugas kolektor pentingnya membayar pajak itu untuk pembangunan kegiatan daerah, maka saya sering bayar dan ada unsur ketakutan kepada kepala desa, karena yang sering menunggak akan berurusan dengan kepala desa”

Kemudian menurut Bapak Koko selaku bagian penagihan Pajak PBB di Badan Pendapatan Daerah (BAPENDA) mengatakan :

"peran petugas kolektor desa sangat dapat meningkatkan kepatuhan dalam membayar Pajak PBB, semakin banyak wajib pajak yang patuh maka target akan segera tercapai. Dan petugas kolektor sangat membantu dalam pencapaian target penerimaan bisa dibilang petugas kolektor merupakan perpanjangan tangan dari BAPENDA kepada wajib pajak"

Berdasarkan hasil wawancara diatas bahwa peran petugas kolektor desa dalam meningkatkan kepatuhan wajib pajak dalam membayar Pajak PBB dikecamatan jalancagak, dikecamatan subang dan kecamatan serangpanjang. sudah dilaksanakan dengan baik berdasarkan tugas pokok dan ungsi yang diberikan tetapi hasilnya belum maksimal. Hal ini dapat ditunjukan peran petugas sangat membantu dalam meningkatkan kepatuhan wajib pajak dalam membayar Pajak Bumi Dan Bangunan (PBB-P2) tetapi dalam pemungutannya petugas kolektor menyebutkan ada Wajib pajak yang belum atau tidak memahami prosedur administrasi perpajakan dan belum maksimalnya peran dari perangkat desa dalam mensosialisasikan, pembinaan dan pengawasan guna pencapaian target penerimaan Pajak Bumi dan Bangunan akan pentingnya membayar Pajak Bumi dan Bangunan (PBB-P2).

Analisis Hambatan - Hambatan dalam meningkatkan Kepatuhan Wajib Pajak dalam membayar Pajak Bumi dan Bangunan (PBB-P2).

Faktor yang mempengaruhi dalam meningkatkan kepatuhan wajib pajak dalam membayar Pajak Bumi dan Bangunan (PBB-P2) dikecamatan Jalancagak, dikecamatan Subang dan kecamatan Serangpanjang. disebabkan oleh dua faktor. Yaitu faktor internal dan faktor eksternal. Faktor internal merupakan faktor yang berasal dari dalam diri manusia. Sedangkan faktor ekstenal merupakan faktor yang dari luar diri manusia. Biasanya faktor dari dalam terjadi kesalahan dari diri sendiri manusia sedangkan faktor eksternal terjadi bukan dari diri manusia melainkan faktor dari luar manusia.

faktor internal yang terjadi dalam meningkatkan kepatuhan wajib pajak sehingga tidak tercapainya target diantaranya sebagai berikut :

1. Kurangnya Pemahaman Tugas Fokok Dan Fungsi Petugas Kolektor Desa

2. Minimnya upah Administrasi untuk petugas kolektor

3. Waktu penagihan yang kurang jelas

Faktor ekstenal merupakan faktor yang terjadi secara tidak langsung sehingga berdampak pada ketidakpatuhan wajib pajak diantaranya sebagai berikut :

1. Kurangnya kesadaran wajib pajak dalam membayar pajak bumi dan bangunan

2. Kurangnya pemahaman wajib pajak mengenai pajak bumi dan bangunan

3. Keadaan perekonomian wajib pajak

4. Keberadaan Subjek pajak

5. Data tidak sesuai dengan objek pajak yang dimiliki.

6. Surat Pemberitahuan Pajak Terutang (SPPT) Ganda

7. Pemekaraan Wilayah 


\section{Analisis Upaya Strategi dalam meningkatkan Kepatuhan Wajib Pajak dalam membayar Pajak Bumi dan Bangunan (PBB-P2).}

Adapun Upaya yang harus dilakukan dalam meningkatkan kepatuhan wajib pajak dalam membayar pajak PBB tersebut diantaranya sebagai berikut :

1. Memberikan penyuluhan atau sosialisasi

2. Meningkatkan tingkat pelayanan Pajak Bumi dan Bangunan

3. Pemberian sanksi

\section{KESIMPULAN}

Peran petugas kolektor desa dalam meningkatkan kepatuhan wajib pajak dalam membayar pajak bumi dan bangunan dikabupaten subang, dengan studi kasus dikecamatan Subang, kecamatan Jalancagak dan kecamatan Serangpanjang sudah dilaksanakan tetapi belum maksimal. Belum maksimalnya dilihat berdasarkan hambatan - hambatan yang terjadi, baik hambatan internal maupun hambatan eksternal.

\section{DAFTAR PUSTAKA}

Amelia, Reski. 2019. Sistem dan Prosedur Pemungutan Pajak Bumi Dan Bangunan Dalam Meningkatkan Pendapatan Asli Daerah Kota Samarinda. eJournal Ilmu Pemerintahan, Volume 7, Nomor 4, 2019: 1539-1552

Anwar, Chairil.2013. Manajemen Perpajakan Strategi Perencanaan Perpajakan Edisi Revisi. PT.Gramedia'

Arta, Phaureula Wulandari \& Emy Iryanie.2018.Pajak Daerah Dalam Pendapatan Asli Daerah. Cetakan Pertama. Deepublish

Ismail Tjip. 2018. Potret pajak Daerah. Edisi Pertama. KencanaJosep. 2018. Pemerintahan Mengalihkan Pajak Bumi dan Bangunan Perdesaan dan Perkotaan (PBB-P2) Sebagai Pajak Daerah. Indocamp

Josep. 2018. Pemerintahan Mengalihkan Pajak Bumi dan Bangunan Perdesaan dan Perkotaan (PBBP2) Sebagai Pajak Daerah. Indocamp

Karmila.2018. Mengenal perpajakan. Cempaka Putih

Kolatung, Julia Filia. 2021. Analisis Tingkat Kepatuhan Wajib Pajak Bumi dan Bangunan dikota Manado. Jurnal EMBA Vol.9 No 2 April 2021, Hal. 1006-1014

Kusnanto,2019. Belajar Pajak.Penerbit Mutiara Aksara

Langi, Veronita., Robert Winerungan Firda Magda Sumual. 2020. Analisis Partisipasi Wajib Pajak Bumi dan Bangunan Didesa Sion Kecamatan Tompasbaru. JAIM: Jurnal Akuntansi Manado, Vol. 1 No. 3 Desember 2020

Sedarmayanti. 2013. Kinerja Petugas Pajak Bumi dan Bangunan dikecamatan Cibatu Kabupaten Purwakarta. Jurnal administrasi, Volume X, Nomor 3, Desember 2013.

Sumarsan, Thomas. 2017. Perpajakan indonesia,jakarta : indeks

Wahyuni, Tuti. 2018. Peranan Petugas Kolektor Desa dalam meningkatkan Kepatuhan Wajib Pajak untuk membayar Pajak Bumi dan Bangunan Perdesaan dan Perkotaan (PBB-P2) didesa Kelapasawit Kecamatan Lakbok Kabupaten Ciamis. Jurnal Moderat, Volume 4, Nomor 4, November 2018, hlm 81-88. 